\title{
Osteoprotegerin ligand and osteoprotegerin: novel implications for osteoclast biology and bone metabolism
}

\author{
Lorenz C Hofbauer \\ Division of Gastroenterology and Endocrinology, Philips University, D-35033 Marburg, Germany \\ (Correspondence should be addressed to L C Hofbauer, Endocrine Research Unit, Division of Gastroenterology and Endocrinology, \\ Zentrum für Innere Medizin, Philips University, Baldingerstrasse, D-35033 Marburg, Germany; Email: hofbauer@post.med.uni-marburg.de)
}

\section{Introduction}

The integrity of the skeleton depends upon bone remodeling, the permanent and controlled resorption of bone by osteoclasts (OC) and its subsequent replacement by bone-forming osteoblasts. An imbalance between bone resorption and bone formation results in osteoporosis (if bone resorption exceeds bone formation) or osteopetrosis (if bone formation exceeds bone resorption). The regulation of the balance between osteoblastic and osteoclastic activity is critical for the understanding of normal bone cell biology and forms the cellular basis of the pathogenesis of metabolic bone diseases.

A variety of local growth factors and cytokines as well as systemic peptide and steroid hormones regulate the differentiation of immature precursor cells and the activity of mature cells in both the osteoblastic and the osteoclastic lineage $(1-7)$. The differentiation of OC precursors from a macrophage-like stem cell into the mature multinucleated OC (osteoclastogenesis) depends on various local factors secreted by bone marrowresiding pluripotent stromal cells and mature osteoblasts $(1-3,7)$. Regulation of osteoclastogenesis (and OC activity) by osteoblastic factors may therefore couple osteoclastic bone resorption to osteoblastic bone formation, and may constitute a local regulatory mechanism for bone remodeling.

During the last decade evidence has emerged that osteoclastogenesis requires the presence of stromal cells, $1 \alpha, 25$-dihyroxyvitamin $\mathrm{D}_{3}\left(1 \alpha, 25-(\mathrm{OH})_{2} \mathrm{D}_{3}\right)$ and glucocorticoids in vitro $(1-3,7)$. Although extensive in vitro studies and animal experiments using knock-out or transgenic mice have identified various candidate cytokines that are capable of regulating osteoclastogenesis (and are variably produced by stromal cells treated with $1 \alpha, 25-(\mathrm{OH})_{2} \mathrm{D}_{3}$ and/or glucocorticoids), until recently no single cytokine has been identified that is both necessary and sufficient to induce osteoclastogenesis. The recent discovery of osteoprotegerin (OPG)/ osteoclastogenesis inhibitory factor (OCIF) $(8,9)$, a soluble member of the tumor necrosis factor (TNF) receptor (TNFR) superfamily, and the subsequent identification of its cognate ligand, osteoprotegerin ligand (OPG-L)/osteoclast differentiation factor (ODF)
$(10,11)$ (Table 1), has provided new insights into the regulation of osteoclastogenesis. TNF-related ligands and their receptors are critical for various aspects of cell survival and cell death (12).

This review summarizes the rapidly evolving progress made in our understanding of OPG/OCIF and OPG-L/ ODF, including their protein and gene organization, their expression and regulation, and their effects both in vitro and in vivo. These novel findings have led to a new paradigm of osteoclast biology with major novel implications for bone metabolism and the pathogenesis of metabolic bone diseases.

\section{Osteoprotegerin/osteoclastogenesis inhibitory factor}

\section{Identification of OPG/OCIF}

OPG/OCIF was identified independently by several groups $(8,9,13-16)$. Based on sequence homology, Simonet et al. (8) identified OPG as a novel TNFR superfamily member during a sequencing project of rat intestinal cDNA. This was followed by sequence analysis of the rat, the mouse and the human OPG cDNA (8). Using a protein purification approach of medium from the human lung fibroblast cell line IMR-90, Tsuda et al. (15) initially identified OCIF as a heparin-binding basic glycoprotein. The same group subsequently cloned the human OCIF cDNA by screening an IMR-90 cDNA library (9). In addition, OPG/OCIF was also identified by Tan et al. (13) by screening various cell line libraries and Kwon et al. (14) by screening an expressed sequence tag database for homologous regions for the cysteine-rich motifs of the TNFR, and was named TNF receptorrelated molecule-1 (TR1). Yun et al. (16) cloned OPG/ OCIF from a follicular dendritic cell (FDC)-like cell line FDC-1 and named it FDC receptor-1 (FDCR-1).

\section{OPG/OCIF protein and gene organization}

Functional characterization of the OPG/OCIF protein The OPG/OCIF propeptide from human, mouse and rat consists of 401 amino acids $(8,9,13$, 14). The human and the mouse OPG/OCIF proteins are $85 \%$ and $94 \%$ identical to the rat OPG/OCIF protein 
Table 1 Glossary of abbreviations used

\begin{tabular}{llc}
\hline Abbreviation & \multicolumn{1}{c}{ Definition } & Reference \\
\hline DC & Dendritic cell(s) & $(16)$ \\
FDCR-1 & Follicular dendritic cell receptor-1 (syn. OPG) & \\
OC & Osteoclast(s) & $(9)$ \\
OCIF & Osteoclastogenesis inhibitory factor (syn. OPG) & $(58)$ \\
ODAR & Osteoclast differentiation and activation receptor (syn. RANK) & $(11)$ \\
ODF & Osteoclast differentiation factor (syn. OPG-L) & $(8)$ \\
OPG & Osteoprotegerin (syn. OCIF) & $(10)$ \\
OPG-L & Osteoprotegerin ligand (syn. ODF) & $(47,57)$ \\
RANK & Receptor activator of NF- $k$ B (syn. ODAR) & $(47)$ \\
RANKL & Receptor activator of NF- $k$ B ligand (syn. OPG-L) & \\
TNF & Tumor necrosis factor & $(13,14)$ \\
TNFR & Tumor necrosis factor receptor & $(64)$ \\
TR1 & TNF receptor-related molecule (syn. OPG) & $(28)$ \\
TRAF & TNF receptor-associated factor & $(46)$ \\
TRAIL & TNF-related apoptosis-inducing ligand & \\
TRANCE & TNF-related activation-induced cytokine (syn. OPG-L)
\end{tabular}

Syn, synonym.

which indicates a high degree of conservation during evolution (8). Post-translationally the 21 amino acid signal peptide is cleaved, generating the mature OPG/ OCIF peptide of 380 amino acids $(8,14)$. Based on its hydrophobicity profile, OPG/OCIF lacks transmembrane and cytoplasmic domains, and is a secreted protein $(8$, $9,13,14)$. Alignment analysis of the amino acid sequence of TNFR superfamily members revealed that the N-terminal portion of OPG/OCIF is most homologous to TNFR-2 and CD40 (8). The N-terminal end has four repeats of cysteine-rich motifs $(8,9,13,14)$. These cysteine-rich motifs which consist of four to six cysteine pairs within the domains form intra-chain disulfide bridges which in CD40 have been implicated in the formation of 'tethered-loops' at both ends of each domain (13). In contrast, the C-terminal portion shares no homology with any other TNFR superfamily members except for two death domain homologous (DDH) tandem regions in the 204 C-terminal residues which have a high homology to Fas and TNFR-1 (9).

OPG/OCIF is a glycoprotein with four (8) or five (14) potential N-glycosylation sites. OPG/OCIF is synthesized as a monomer and assembled as a homodimer within the cell, and then secreted mainly as a disulfide-linked homodimer into the extracellular compartment, although small amounts of the OPG/OCIF monomer are present in the cell medium (8). Of note, Yun et al. (16) recently also reported the presence of membranebound OPG/OCIF on the surface of transfected kidney cells and a non-transfected dendritic cell (DC) line.

The OPG/OCIF monomer migrates at 55-62 kDa $(8$, $14,15)$ under reducing conditions and at $40 \mathrm{kDa}$ following removal of the N-glycosylation sites $(8,14$, $15)$, while the OPG/OCIF homodimer migrates at 110$120 \mathrm{kDa}$ under non-reducing conditions $(8,15)$. Functional analysis of recombinant human OPG/OCIF expressed in $\mathrm{CHO}$ cells indicated that both the OPG/
OCIF monomer and the homodimer had similar heat and acid stabilities, sialic acid contents, and biological activities as assessed by their ability to inhibit osteoclastogenesis in vitro $(15,17)$. The OPG/OCIF homodimer displayed a higher heparin-binding ability and a higher calcium-lowering potency in normal rats while the monomer had a longer half-life following intravenous administration and a higher area under the curve value (17).

Analysis of the human OPG/OCIF protein has demonstrated the presence of seven distinct protein domains, the N-terminal domains 1 to 4 , each of which contains one of the four cysteine-rich motifs, domains 5 and 6, each containing one DDH region, and the C-terminal domain 7 (18). Analysis of the structure-function relationship of the OPG/OCIF protein revealed that the integrity of all four cysteine-rich motifs at the N-terminus is necessary and sufficient for the inhibition of osteoclastogenesis, whereas truncation of the C-terminal portion to residue 194 does not alter it $(8,18)$. The C-terminal domains 5 to 7 have the potential to mediate cytotoxicity when fused with the transmembrane region of Fas (18); however, it is unclear whether the genuine OPG/OCIF that lacks a transmembrane membrane is involved in cytotoxicity. Domain 7 harbors the heparin-binding site which does not correlate with the bioactivity of OPG/OCIF and a cysteine residue (position 400) which is required for homodimer formation (18).

OPG/OCIF gene organization The human and mouse OPG/OCIF genes are single copy genes containing five exons which are distributed over $29 \mathrm{~kb}(18-20)$. The human OPG/OCIF gene has been localized to chromosome 8q23-24 $(8,14)$, a gene locus harboring a cluster of bone-related genes, including genes implicated in hereditary multiple exostoses, certain types of 
chondrosarcoma, and the gene encoding bone morphogenetic protein (BMP)-1 (8). The exon/intron organization has recently been reported for the human $(18,19)$ and the mouse OPG/OCIF gene (20). The human OPG/ OCIF gene has one major transcription-initiation site located 67 nucleotides up-stream of the ATG codon and two minor transcription-initiation sites at positions 646 and 667 , suggesting the presence of two promoters (19). The mouse OPG/OCIF gene has one major transcription-initiation site located 200 nucleotides up-stream of the ATG codon and two minor transcription-initiation sites at positions 237 and 182 (20).

In the human OPG/OCIF gene, exon 1 encodes ten amino acid residues of the signal peptide, exon 2 encodes the first two cysteine-rich domains and $73 \%$ of the third, while exon 3 encodes the remainder of the third and the fourth cysteine-rich domain (19). Coding of more than one cysteine-rich motif by a single exon has been previously reported for human nerve growth factor receptor, but not for other TNFR members (19). Exon 4 encodes the majority of the first DDH, whereas exon 5 encodes the remainder of the first and the second $\mathrm{DDH}$, and contains the translation-termination codon (19). Of note, exon 4 is in part a duplication of exon 5 (19). Compared with the human OPG/OCIF cDNA (19), the untranslated region of the mouse OPG/OCIF cDNA contains an additional 529 bp (20).

The most abundant OPG/OCIF mRNA species has a size between 2.2 and $3.0 \mathrm{~kb}(8,9,13,14)$. The variability is due to the alternative use of transcription-initiation sites (19). Two additional OPG/OCIF mRNA species, a $6.5-6.6 \mathrm{~kb}$ mRNA and a $4.2-4.4 \mathrm{~kb}$ mRNA are present in some tissues and are usually less abundant in all tissues or cell lines examined (9). These longer transcripts contain the $3^{\prime}$-half of intron 2 (4.2$4.4 \mathrm{~kb}$ fragment) or the entire intron $2(6.5-6.6 \mathrm{~kb}$ fragment) (19).

\section{Tissue and cellular expression of OPG/OCIF}

OPG/OCIF is expressed in a variety of tissues and cell systems and is not restricted to bone $(8,9,13,14)$. Among human fetal tissues, OPG/OCIF mRNA is highly expressed in the lung, the kidneys, the liver and the brain (9). In adult human tissues, high levels of OPG/ OCIF mRNA have been detected in the heart, the lung, the kidneys, and bone $(8,9,13,14)$. Other adult tissues that express high OPG/OCIF mRNA levels include the placenta, the liver, the thyroid gland, the spinal cord, and the brain $(8,9,14)$. In addition, OPG/OCIF mRNA is expressed in various immune and hematopoietic tissues, and mesenchymal organs $(8,9)$. In mice, OPG/ OCIF mRNA levels are high in the heart, lung, kidney, liver, brain, placenta, stomach, intestine, skin, and calvaria (8). Analysis of a whole mouse embryo demonstrated increased OPG/OCIF gene expression on day 7 , which decreased by day 11 , and increased again by day 15 (8). A detailed study by Mizuno et al. (20) demonstrated that OPG/OCIF mRNA in the mouse fetus is expressed at day 8.5, while it is expressed in the maternal decidua as early as day 5.5. As assessed by in situ hybridization in a day-15 mouse embryo, OPG/ OCIF mRNA was localized to the cartilaginous aspects of developing bone, the aorta and other large arteries, the skin, and the gastrointestinal tract (8).

OPG/OCIF mRNA levels have been detected in various human and murine primary cells and cell lines which, in part, reflect the tissue expression of OPG/OCIF, including various osteoblastic lineage cell lines such as the marrow stromal cell lines ST-2 (9), MC3T3-E1 (9), TF274 (13), and hMS (21), the osteosarcoma cell lines MG-63 (13, 14, 22, 23) and SaOS-2 (23), and various normal human osteoblastic cells lines (hFOB, hFOB/ER-9) $(21,24)$ as well as primary human trabecular osteoblasts $(21,23)$. Of interest, some of the conditionally immortalized cell lines express tenfold higher OPG/OCIF mRNA levels when cultured under differentiating conditions $(21,24)$. Among osteoblastic lineage cells, the osteosarcoma cell line MG-63 produces the most abundant amounts of OPG/OCIF (22). Other cells that express high OPG/OCIF mRNA levels include primary endothelial cells $(13,14)$, human aorta smooth muscle cells (14), the embryonic pulmonary fibroblastic cell line IMR-90 $(9,15)$ and primary fibroblasts (14), the monocytic leukemia cell line THP-1 $(13,14)$, the ovarian cancer cell line CAOV-3 (14), the breast cancer cell line MCF7 (13), and several lymphoma cell lines (13). In the immune system, OPG/OCIF expression is restricted to lymphoid cells, and is most abundant in $\mathrm{B}$ cells, DC, and follicular DC-enriched fractions.

\section{Biological effects of OPG/OCIF}

\section{Genetic models}

Overexpression of OPG/OCIF in transgenic mice An important role of OPG/OCIF in the regulation of bone metabolism has been derived from the phenotype of transgenic mice overexpressing OPG/OCIF (8). Overexpression of $\mathrm{OPG} / \mathrm{OCIF}$ resulted in early, progressive osteopetrosis at various skeletal sites, including the long bones, vertebrae, and the pelvis (8). In contrast to other animal models of osteopetrosis, these transgenic mice displayed no other skeletal or extraskeletal abnormalities, except for splenomegaly which was due to compensatory extramedullary hematopoiesis (8).

Histologically, a systemic increase in mineralized trabecular bone was noted in mice overexpressing OPG/OCIF, including areas where hematopoiesis normally occurs (8). The most intriguing histological finding was a marked decrease in the number of trabecular OC, whereas the number of other hematopoietic cells of the monocyte-macrophage lineage was normal (8). This indicates that overexpression of OPG/ OCIF increased bone mass mainly by inhibiting the terminal stage(s) of OC differentiation. 
Deletion of OPG/OCIF in knock-out mice Two recent studies have demonstrated that OPG/OCIF knock-out mice develop severe, early onset osteoporosis $(25,26)$. Using a targeting vector which replaced the portion of exon 2 encoding the first two cysteine-rich domains of OPG/OCIF, Bucay et al. (25) and Mizuno et al. (26) generated viable and fertile OPG/OCIF-deficient mice $(25,26)$. OPG/OCIF-deficient mice had an increased postnatal mortality associated with an increased incidence of vertebral and enchondral bone fractures. OPG/OCIF-deficient mice were normal at birth, suggesting that OPG/OCIF deficiency did not affect embryogenesis or organogenesis $(25,26)$. Postnatally, OPG/OCIFdeficient mice had a decreased bone mineral density with thin cortical bone in the femur and the pelvis, and destruction of the femoral growth plates. They also suffered from multiple fractures, particularly involving the long bones as early as the first (25) or second month of life (26). Older mice had severe deformities of the vertebral column due to serial compression fractures of the vertebral bodies, leading to marked kyphosis. They also developed collapsed epiphyses of the distal femur (25).

Trabecular bone mineral density at 2 months of age was decreased in OPG/OCIF-deficient mice by $45 \%$ compared with wild-type littermates whereas cortical bone density was reduced by 19\% (25). Of note, total body bone density of 6-month-old heterozygous mice was $6 \%$ lower than that of wild-type animals, suggesting that even the loss of a single allele of OPG/OCIF results in significant bone loss (25). In the second study, the femurs of 13-week-old OPG/OCIF-deficient male mice had a $28 \%$ lower bone mineral density and both bone strength and stiffness were reduced by more than $50 \%(26)$.

Histologically, the bones of OPG/OCIF-deficient mice were markedly osteoporotic and almost completely lacked trabecular bone after 2 months of life $(25,26)$. Loss of cancellous bone in OPG/OCIF-deficient mice became apparent even by the first week of life, while cortical bone became osteoporotic by 4 weeks of age (25). Further histological findings included the presence of numerous OC $(25,26)$ and osteoblasts (25) surrounding an increased number of cortical vessels, replacement of lamellar bone with woven bone in the cortex, and increased osteocyte density, consistent with increased bone turnover (25). This was confirmed by bone histomorphometry, which revealed increased osteoclastic and osteoblastic activity in OPG/OCIFdeficient mice, and serum alkaline phosphatase levels were more than fourfold higher than in wild-type mice (25). These data are consistent with an enhanced osteoclastic bone resorption (due to unopposed effects of OPG-L/ODF which would normally be neutralized by OPG/OCIF) with compensatory increased osteoblastic bone formation.

Surprisingly, OPG/OCIF-deficient mice had arterial calcification in the large arteries by 2 weeks of age. This was followed by profound calcification by 2 months of life in as many as $60 \%$ of the OPG/OCIF-deficient mice (25). Arterial calcification in 6-month-old OPG/OCIFdeficient littermates affected the aorta and the renal arteries, was mainly limited to the media of the artery, and was associated with intimal and medial proliferation and partial aortic dissection (25). Of interest, OPG/ OCIF had previously been localized by in situ hybridization of a mouse embryo to the media of these arteries (8). No vascular abnormalities were reported in the second study (26).

\section{Exogenous administration of OPG/OCIF}

In vitro effects of $O P G / O C I F$ As shown in Fig. 1, the major effects of OPG/OCIF include inhibition of the terminal stages of osteoclastogenesis from OC precursors $(8,9,14,15,18,27-29)$ and the activity of mature OC $(10,14,30,31)$. Simonet et al. (8) were the

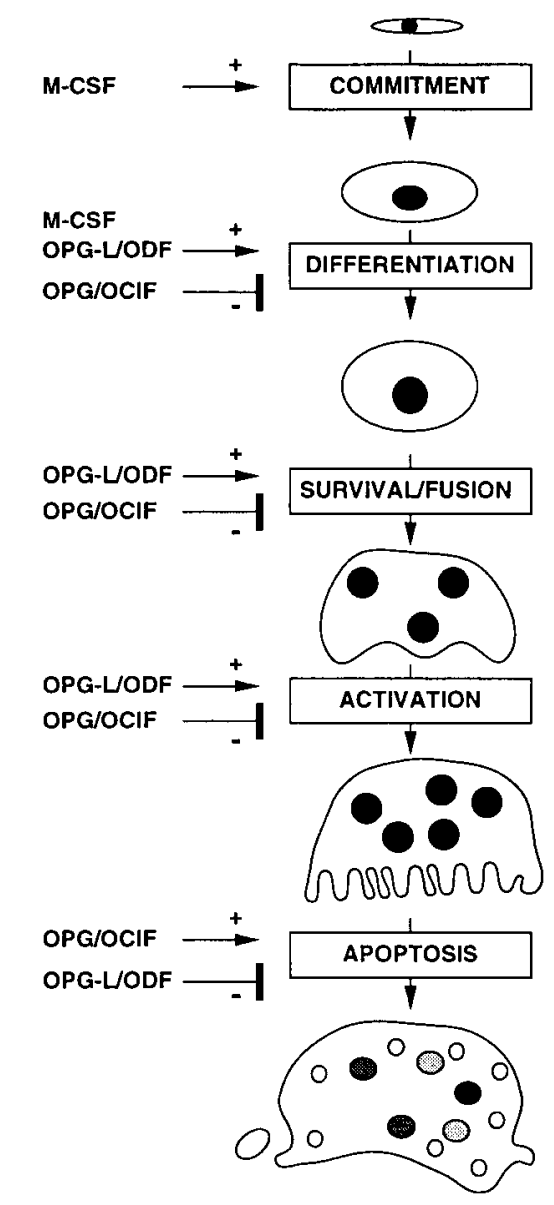

Figure 1 Birth and death of an osteoclast. Differential regulation by OPG/OCIF, OPG-L/ODF, and M-CSF. Following initial commitment from pluripotent stem cells, osteoclast precursor cells undergo sequential differentiation, fusion, and activation. Finally, activated osteoclasts are inactivated by the induction of apoptosis. OPG-L/ ODF and OPG/OCIF regulate these processes in opposite directions. 
first to demonstrate an inhibition of the development of tartaric acid-resistant acid phosphatase (TRAP)-positive OC and TRAP activity in an osteoclastogenesis assay using a spleen cell/bone marrow stromal cell co-culture system following the administration of an OPG-Fc fusion protein. At a concentration of $10-100 \mathrm{ng} / \mathrm{ml}$, OPG-Fc fusion protein completely prevented the OC formation (8). TRAP activity was inhibited by $50 \%$ at a concentration of $1 \mathrm{ng} / \mathrm{ml}$ (8). Of interest, the bioactivity of OPG/OCIF required the presence of residues Nterminal to cysteine 185 which encodes a TNFR-like domain (8). Tsuda et al. (15) using OPG/OCIF purified from cultured medium of fetal lung fibroblasts reported inhibition of osteoclastogenesis at concentrations ranging from 1 to $40 \mathrm{ng} / \mathrm{ml}\left(\mathrm{ED}_{50}\right.$ at 4 to $\left.6 \mathrm{ng} / \mathrm{ml}\right)$. Both the monomer and the homodimer of OPG/OCIF had comparable bioactivities (15). The sensitive period for OPG/OCIF actions during in vitro osteoclastogenesis over 11 days appears to be days 5 through 11, whereas addition of OPG/OCIF from days 0 to 3 or on days 7 and 8 did not affect the numbers of OC formed (32). A similar time-course with a slightly different result was also reported by Yasuda et al. (9). One recent study suggested that OPG/OCIF also decreased OC survival by inducing apoptosis (Fig. 1), which could be prevented by a specific inhibitor of caspase-3, which is critical for apoptosis (32). OPG/OCIF has subsequently been shown to inhibit osteoclastogenesis induced by $1 \alpha, 25(\mathrm{OH})_{2} \mathrm{D}_{3}$ $(14,15)$, prostaglandin $(\mathrm{PG}) \mathrm{E}_{2}(14,29)$, parathyroid hormone (PTH) $(14,15)$, interleukin (IL)-1 (14), and IL$11(14,15)$. The potent inhibitory effect of OPG/OCIF on osteoclastogenesis has recently been demonstrated in the preosteoclastic macrophage-like cell line $\mathrm{C} 7$, in which OPG/OCIF is the single most potent inhibitory factor (27).

In addition, OPG/OCIF was also found to inhibit the pit-forming activity of mature OC $(14,31,33)$. Moreover, OPG/OCIF also inhibited ${ }^{45} \mathrm{Ca}$ release from a mouse fetal long bone organ culture model stimulated by $1 \alpha, 25(\mathrm{OH})_{2} \mathrm{D}_{3}(14,30), \mathrm{PGE}_{2}(30)$, PTH (30), and IL-1 $\alpha$ (30). Bone resorption by OC was inhibited by OPG, and stimulation of OC by OPG-L/ODF was blocked by OPG/OCIF (33). These effects, however, required higher concentrations of OPG/OCIF ranging from 50 to $1000 \mathrm{ng} / \mathrm{ml}(14,30,31)$. Treatment of isolated mature OC with OPG/OCIF reduced or disrupted the formation of the F-actin ring which is correlated with their boneresorbing capacity (31). The inhibition by OPG/OCIF of bone resorption by mature $\mathrm{OC}$ is explained by the biological effects of the OPG-L/ODF to directly stimulate the activity of mature $\mathrm{OC}$ which are counteracted by OPG/OCIF (10).

Regulation by OPG/OCIF of proliferation and differentiation of non-osteoclastic lineage cells has been extensively studied by Tsuda et al. (15). OPG/OCIF had no effect on marrow stromal cell lines (ST-2, MC3T3E1) and various cell lines of mesenchymal origin. In contrast, Kwon et al. (14) recently reported a threefold increase in proliferation of human foreskin fibroblasts following treatment with OPG/OCIF $(200 \mathrm{ng} / \mathrm{ml})$ which could be prevented by co-treatment with a monoclonal antibody against OPG/OCIF. In addition, OPG/OCIF which has been demonstrated to be a soluble receptor for TNF-related ligand (TRAIL), inhibits TRAIL-induced apoptosis of the Jurkat T cell line (28).

In vivo effects of OPG Treatment of 4-week-old mice with daily subcutaneous injections of recombinant murine OPG/OCIF (10 mg/kg per day) for 7 days resulted in a threefold increase in the trabecular bone mass at the proximal tibial metaphysis (8). This increase following exogenous administration of OPG/OCIF was even higher than that following pamidronate administration, and occurred at a serum steady-state OPG/OCIF level of $320 \pm 176 \mathrm{ng} / \mathrm{ml}$ (8). Similar effects have also been reported by Yasuda et al. (9) who treated 5-weekold rats with recombinant OPG/OCIF $(24 \mathrm{mg} / \mathrm{kg}$ per day) for 2 weeks and demonstrated a 1.5-fold increase of bone mineral density and a 1.8 -fold increase of bone volume at the proximal tibial metaphysis (9). In addition, the administration of recombinant murine OPG/OCIF ( $5 \mathrm{mg} / \mathrm{kg}$ per day) for 2 weeks following ovariectomy increased bone volume and decreased OC number, suggesting that OPG/OCIF prevented estrogen deficiency-induced osteoclastic bone resorption (8).

OPG/OCIF has been reported to inhibit osteoclastic bone resorption in various states of normal $(17,36)$ and increased bone resorption, including during normal linear bone growth (34), following the administration of IL-1 (34) or OPG-L/ODF (10), after thyroparathyroidectomy and subsequent challenge with PTH- and $1 \alpha, 25-(\mathrm{OH})_{2} \mathrm{D}_{3}(35)$, and in humoral hypercalcemia of malignancy $(34,36)$. The rapid onset of the hypocalcemic effect in these studies suggests a direct effect of OPG/OCIF on OC activity (35).

\section{Regulation of OPG/OCIF by systemic hormones and factors}

Given the phenotype of osteopetrosis in transgenic mice overexpressing OPG/OCIF (8) and of osteoporosis in OPG/ OCIF knock-out mice $(25,26)$, OPG/OCIF has been considered an obvious candidate cytokine receptor which mediates the stimulatory or inhibitory effects of various systemic hormones and cytokines on osteoclastogenesis (Table 2). OPG/OCIF mRNA and protein levels were stimulated in various human osteoblastic cell systems by $1 \alpha, 25-(\mathrm{OH})_{2} \mathrm{D}_{3}(21), \mathrm{BMP}-2(21), \mathrm{IL}-1 \alpha$ (37) and $-\beta(21)$, and TNF- $\alpha(21,38)$ and TNF- $\beta$ (38). Other studies using murine osteoblastic/stromal cells demonstrated downregulation of OPG/OCIF mRNA levels in marrow stromal cell lines (ST-2, tsJ2) by $1 \alpha, 25-(\mathrm{OH})_{2} \mathrm{D}_{3}(9,39)$, but not in primary osteoblasts (39) as well as down-regulation of OPG/OCIF mRNA levels in primary osteoblasts by $1 \alpha, 25-$ $(\mathrm{OH})_{2} \mathrm{D}_{3}$, IL- $1 \alpha$, and PTH (40). Some of these discrepancies may be due to species differences or may reflect the 
Table 2 Regulation of OPG/OCIF

\begin{tabular}{|c|c|c|}
\hline Stimulation & Cells & Reference \\
\hline $\begin{array}{l}\text { BMP-2 } \\
\text { Calcium chloride } \\
1 \alpha, 25-(\mathrm{OH})_{2} \mathrm{D}_{3} \\
17 \beta-\text {-Estradiol } \\
\text { IL- } 1 \alpha \\
\text { IL-1 } \beta \\
\text { Phorbol 12-myristate } 13 \text {-acetate } \\
\text { Transforming growth factor- } \beta \\
\text { TNF- } \alpha \\
\text { TNF- } \beta\end{array}$ & $\begin{array}{l}\text { hFOB } \\
\text { IMR-90, ST-2, MC3T3-E1 } \\
\text { hFOB, hOB } \\
\text { hFOB/ER-9, hOB } \\
\text { MG-63, hOB } \\
\text { hFOB, human fibroblasts } \\
\text { Kidney cell lines } \\
\text { MC3T3/G2/PA6, ST-2, MC3T3-E1, KS483, murine primary osteoblasts } \\
\text { hFOB, MG-63, human fibroblasts } \\
\text { MG-63 }\end{array}$ & $\begin{array}{c}(21) \\
(9) \\
(21) \\
(24) \\
(37) \\
(21,14) \\
(13) \\
(40,44) \\
(21,38,14) \\
(38)\end{array}$ \\
\hline Inhibition & Cells & Reference \\
\hline $\begin{array}{l}\text { Dexamethasone } \\
1 \alpha, 25-(\mathrm{OH})_{2} \mathrm{D}_{3} \\
\text { Hydrocortisone } \\
\text { IL-1 } \alpha \\
\text { PGE }_{2} \\
\text { PTH }^{\text {PTH }}\end{array}$ & $\begin{array}{l}\text { hFOB, hOB, hMS, ST-2 } \\
\text { ST-2, tsJ2, murine primary osteoblasts } \\
\text { hOB, MS, MG-63 } \\
\text { Murine primary osteoblasts } \\
\text { MS, murine primary osteoblasts } \\
\text { Murine primary osteoblasts }\end{array}$ & $\begin{array}{c}(22,23,40) \\
(39,40) \\
(23) \\
(40) \\
(45,40) \\
(40)\end{array}$ \\
\hline
\end{tabular}

Abbreviations: hFOB/ER-9, human fetal osteoblastic cell line stably transfected with the estrogen receptor; hOB, primary human trabecular osteoblasts; hFOB, human fetal osteoblastic cell line; hMS, human marrow stromal cell line; IMR-90, human embryonic lung fibroblasts; ST2, tsJ2, and MC3T3-E1, marrow stromal cell lines; MG-63, human osteosarcoma cell line; MS, primary marrow stromal cells.

variability of the cell systems regarding their stage of osteoblastic differentiation.

OPG/OCIF mRNA levels have also been shown to be stimulated by increasing concentrations of calcium chloride in murine marrow stromal cell lines (9). At the local bone level calcium is mainly released from bone at sites of active osteoclastic activity (9), and an increase of OPG/OCIF with inhibition of osteoclastogenesis in response to released calcium ions may constitute an autocrine negative feedback loop to limit the boneresorbing effects of OC. The biological significance of OPG/OCIF induction by IL-1 and TNF in human osteoblasts is less clear $(21,37,38)$, although this has recently also been reported for human foreskin fibroblasts (14). Teleologically, up-regulation of OPG/OCIF production by proinflammatory, bone-resorbing cytokines IL- $1 \beta$ and TNF- $\alpha$ (which also stimulate OPG-L/ ODF production) may represent a mechanism by which the action(s) of these cytokines are counterbalanced (21). Similarly, up-regulation of TNFR family members by TNF ligands has been reported for other family members (41).

Transforming growth factor- $\beta$ (TGF- $\beta$ ) which inhibits osteoclastic bone resorption $(42,43)$ was also found to stimulate the production of OPG/OCIF by various bone marrow stromal cell lines and primary osteoblasts, and subsequently to inhibit osteoclastogenesis $(40,44)$. Moreover, the inhibitory effects of TGF- $\beta$ on osteoclastogenesis were prevented by treatment with an OPG/ OCIF neutralizing antibody, suggesting direct mediation of the anti-resorptive effects of TGF- $\beta$ by OPG/OCIF ( 40 , 44). By contrast, the insulin-like growth factor system which may act as an anabolic growth factor system in bone cells was not found to regulate osteoblastic OPG/
OCIF production (L C Hofbauer, B L Riggs \& S Khosla, unpublished observation).

Of interest, treatment of estrogen-responsive osteoblasts (hFOB/ER-9) with 17 $\beta$-estradiol stimulated OPG/ OCIF mRNA and protein concentrations by fourfold in a dose- and time-dependent fashion (24). These effects could be abrogated by treatment with the specific estrogen receptor antagonist ICI 182,780. In addition, the concentration of OPG/OCIF produced by hFOB/ER-9 cells $(2-8 \mathrm{ng} / \mathrm{ml})$ was in the range where OPG/OCIF had its $\mathrm{ED}_{50}(24)$. As mentioned earlier, the administration of OPG/OCIF completely prevented ovariectomyinduced bone resorption and bone loss (8).

OPG/OCIF production is inhibited by glucocorticoids $(22,23,40)$ and $\mathrm{PGE}_{2}(40,45)$. Inhibition of OPG/OCIF mRNA levels and protein concentrations in human cell systems was robust (by 90\%) and occurred in all human osteoblastic cell systems assessed, including marrow stromal cells, osteoblasts, and the osteosarcoma cell line, MG-63 $(22,23)$. In murine cell systems, dexamethasone decreased OPG/OCIF mRNA levels in the stromal cell line, ST-2, while it had a biphasic effect with an initial decrease and subsequent increase in primary osteoblasts (40). OPG/OCIF mRNA levels were also inhibited by $\mathrm{PGE}_{2}$ in primary human bone marrow stromal cells (45) and primary murine osteoblasts (40).

\section{Osteoprotegerin ligand/osteoclast differentiation factor}

\section{Identification of OPG-L/ODF}

The ligand for OPG/OCIF has recently been identified by two groups $(10,11)$. Using an OPG-fusion protein as an 
immunoprobe, Lacey et al. (10) identified OPG-binding sites on the surfaces of a myelomonocytic cell line, expression cloned murine OPG ligand (OPG-L) cDNA from a myelomonocytic cell library, and subsequently cloned human OPG-L cDNA from a lymph node library. Similarly, Yasuda et al. (11) expression cloned ODF cDNA from a cDNA library of the murine marrow stromal cell line ST-2 following treatment with $1 \alpha, 25(\mathrm{OH})_{2} \mathrm{D}_{3}$ and dexamethasone. Alignment analysis revealed the identity of OPG-L/ODF to two independently cloned members of the TNF ligand family, TNFrelated activation-induced cytokine (TRANCE) (46) and receptor activator of nuclear factor (NF)- $\kappa \mathrm{B}$ ligand (RANKL) (47). TRANCE was identified as an immediate early gene which is induced by stimulation of the T cell receptor (46), while RANKL was identified as an important factor that stimulates the function of DC (47).

\section{OPG-L/ODF protein and gene organization}

Functional characterization of the OPG-L/ODF protein The human and murine OPG-L/ODF are polypeptides of 317 and 316 amino acid respectively $(10,11,46,47)$. Human OPG-L/ODF has an $83-87 \%$ homology to murine OPG-L/ODF, indicating high conservation during the evolution (10, 46, 47). Analysis of OPG-L/ODF revealed the absence of a signal peptide and the presence of a 21- to 24-residue hydrophobic domain which predicts a transmembrane domain $(10,11,46,47)$. OPG-L/ODF is a type II transmembrane protein. Human OPG-L/ODF has a cytoplasmic domain at the N-terminus (residues 148), a transmembrane domain (residues 49-69), and an extracellular region at the C-terminus (residues 70$317)(10,46,47)$. The C-terminal region of OPG-L/ODF contains two functional domains, a stalk region (residues 71-157), and the active ligand site (residues $158-317)(10)$. The active ligand site is predicted to contain ten $\beta$-sheet-forming sequences that are present in all TNF-related proteins $(10,46)$. OPG-L/ODF is most closely related to TNF-related apoptosis-inducing ligand (TRAIL, 20-34\% homology (10, 46); CD40 ligand, $28 \%$ homology (47); Fas ligand, 19\% homology (46)). OPG-L/ODF contains two potential N-glycosylation sites $(46,47)$.

OPG-L/ODF is present in two forms, a cell-associated form (as mentioned above) and a soluble form which is derived from the cell-associated form by posttranslational processing at positons 139 (murine OPGL/ODF) or 140 and 145 (human OPG-L/ODF) (10). The cell-associated form migrates at 40-45 $\mathrm{kDa}(10,11$, 46) while the soluble form migrates at $31 \mathrm{kDa}(10)$. Expression and functional analysis of truncated OPG-L/ ODF variants revealed that truncated forms that contained residues 126, 137, and 158 all bound to OPG/OCIF with a similar affinity, suggesting that the soluble OPG-L/ODF is biologically active (10). Future studies are required to assess whether the soluble OPG-
$\mathrm{L} / \mathrm{ODF}$ form is released by enzymatic cleavage, and, if so, to determine the expression, tissue distribution, and regulation of this putative protease.

OPG-L/ODF gene organization The human OPG-L/ ODF gene has been localized to chromosome 13q14 $(46,47)$. The exon/intron organization of OPG-L/ODF has not been reported to date. The murine full-length OPG-L/ODF cDNA consists of $2237 \mathrm{bp}$ with a Kozak consensus sequence at $137 \mathrm{bp}$ of the $5^{\prime}$ end (46). All studies have confirmed the presence of a single OPG-L/ ODF mRNA species at $2.2-2.4 \mathrm{~kb}(10,11,46-48)$.

Of note, the murine OPG-L/ODF gene promoter contains a binding site for OSF $2 / \mathrm{Cbfa}-1$, an essential transcription factor for osteoblastogenesis (49), and the expression of OPG-L/ODF mRNA depends on the functional activity of Cbfa-1 (50). OPG-L/ODF mRNA levels were absent in Cbfa-1-deficient mice which also had impaired osteoclastogenesis (50). Thus, it is likely that the presence of the OSF2/Cbfa-1-responsive element within the OPG-L/ODF gene promoter may represent a mechanism whereby osteoblastogenesis and osteoclastogenesis are coupled $(49,50)$. Clearly, further studies are needed to define the role of OSF2/ Cbfa-1 and OPG-L/ODF as molecular mediators of bone remodeling.

\section{Tissue and cellular expression of OPG-L/ODF}

OPG-L/ODF gene expression is most abundant in the skeleton (bone, bone marrow) and in lymphoid tissues (lymph node, spleen, thymus, Peyer's patches, fetal liver) $(10,11,46,47)$. Other sites of significant OPG-L/ ODF mRNA expression include heart, skeletal muscle, lung, stomach, placenta, the thyroid gland, and peripheral blood leukocytes $(11,47)$. Consistent with the tissue distribution in humans, high OPG-L/ODF mRNA levels have been detected in lymph node-derived T cells but not in spleen-derived B cells (46). OPG-L/ODF mRNA was also found to be expressed by stromal cells and osteosarcoma cell lines (SaOS-2, MG-63) (10, 22, $46,48)$.

In rodents, OPG-L/ODF mRNA is highly expressed in lymph node, spleen, thymus, and the cerebellum (10). Furthermore, OPG-L/ODF mRNA has been detected in two murine marrow stromal cell lines (ST-2, MC3T3E1), the rat osteosarcoma cell line ROS (10), primary murine calvarial osteoblasts (11), and a variety of primary and transformed murine lymphoid cell lines, and was positively correlated with the content of $\mathrm{T}$ lymphocytes (47). In situ hybridization analysis of a 15.5-day-old mouse embryo localized high OPG-L/ODF mRNA expression to the white splenic pulp, the medulla of the thymus, and the cortical areas of developing lymph nodes, and intestinal lymphoid patches, suggesting that T cell-rich tissues are a major source of OPG-L/ ODF (10). In fetal murine bone, OPG-L/ODF is mainly expressed in the primitive mesenchymal cells adjacent 
to the cartilaginous Anlagen and in hypertrophic chondrocytes within the Anlagen as well as in regions of primary ossification and modeling (10). In adult murine bone, OPG-L/ODF was mainly found in the growth plate and the metaphyseal periosteum, which are areas of high osteoclastic bone resorption and active bone remodeling during growth (10).

\section{Biological effects of OPG-L/ODF}

\section{Genetic models: deletion of OPG-L/ODF in knock-out mice}

Consistent with the effects of OPG-L/ODF (10) and the phenotypes of OPG/OCIF transgenic (8) and knock-out mice $(25,26)$, OPG-L/ODF knock-out mice have severe osteopetrosis and lack mature OC (51). OPG-L/ODF knock-out mice are viable and normal at birth (51). There is generalized increased bone mineral density (osteopetrosis) throughout life and the long bones contain large amounts of cartilage and mineral leading to compensatory extramedullary hematopoiesis (51). Exogenous administration of OPG-L/ODF to OPG-L/ODF knock-out mice can rescue bone abnormalities and induces the differentiation of $O C$, suggesting that $O C$ precursor cells are present, but (in the absence of OPG$\mathrm{L} / \mathrm{ODF}$ ) fail to differentiate towards mature OC (51). In contrast to OPG/OCIF transgenic mice (8), OPG-L/ODF knock-out mice lack teeth, display shorter broad and flat bones, and have immune system abnormalities, including $\mathrm{B}$ and $\mathrm{T}$ cell maturation defect, thymus hypoplasia and lymph node agenesis and hypoplasia (51). The target tissues of OPG-L/ODF deficiency (skeleton, immune system) are identical to those with the most abundant OPG-L/ODF gene expression $(10,11)$.

\section{Exogenous administration of OPG-L/ODF}

In vitro effects of OPG-L/ODF on bone metabolism As shown in Fig. 1, the major in vitro effects of OPG-L/ODF include promotion of differentiation, fusion, activation, and survival of $\mathrm{OC}$ as well as inhibition of OC apoptosis $(10,11,33,52-55)$. In fact, the combination of OPG-L/ $\mathrm{ODF}$ and the permissive factor M-CSF is able to induce the differentiation of mature $\mathrm{OC}$ from pluripotent $\mathrm{OC}$ precursors in vitro in the absence of additional hormones, cytokines, or stromal cells, implying that these two cytokines are both necessary and sufficient for osteoclastogenesis $(10,11,52,53)$. In a murine marrow stromal cell culture, OPG-L/ODF increased TRAP activity and the number of OC identified by positive TRAP cytochemistry $(10,11)$. The $\mathrm{ED}_{50}$ of OPG-L/ODF for these effects was $1 \mathrm{ng} / \mathrm{ml}$ (10). Treatment of OC progenitors with OPG-L/ODF also increased the expression of other $\mathrm{OC}$ differentiation markers, including $\beta_{3}$-integrin, TRAP, cathepsin $\mathrm{K}$, c-src, as well as calcitonin and vitronectin receptors $(10,11,52,53)$. Recently, the stimulation of osteoclastogenesis by OPG-
L/ODF was also demonstrated in human monocytes derived from peripheral blood $(52,53)$, indicating that OPG-L/ODF is active in promoting osteoclastogenesis across species. However, it was shown that the time required for the complete differentiation of OC in human cells is longer (11 days) than that of murine cell systems (7 days) (52). The stimulatory effects of OPG-L/ODF on osteoclastogenesis were dose-related $(10,11,52,53)$, blocked by co-administration of excess OPG/OCIF (10, 11 ), and resulted in functionally active OC, as assessed by their ability to form large resorption lacunae on bone or dentine slices $(10,11,52,53)$.

The rapid onset of changes induced by OPG-L/ODF and OPG/OCIF on bone metabolism indicated that OPGL/ODF may also regulate OC activity. Lacey et al. (10) demonstrated that $\mathrm{OPG}-\mathrm{L} / \mathrm{ODF}$, at a concentration ranging from 1 to $10 \mathrm{ng} / \mathrm{ml}$, activates mature rat $\mathrm{OC}$ to form resorption pits using bovine bone slices in the absence of M-CSF, thus demonstrating that OPG-L/ODF has the potential to stimulate OC activity. This was recently confirmed by Tsukii et al. (30) who demonstrated that OPG-L/ODF dose-dependently increased ${ }^{45} \mathrm{Ca}$ release by mature OC in a fetal mouse long bone culture system. Fuller et al. (33) reported that bone resorption was inhibited by soluble OPG-L/ODF receptor and OPG, and stimulation of the OC activity by OPG-L/ ODF was blocked by OPG.

In vivo effects of OPG-L/ODF on bone metabolism The subcutaneous administration of recombinant OPG-L/ ODF to normal mice caused early onset (within 1 day), severe hypercalcemia in a dose-dependent fashion, suggesting that OPG-L/ODF directly stimulates the activity of mature OC (10). In further support of this, administration of OPG/OCIF to normocalcemic animals $(17,36)$, OPG-L/ODF-treated mice (10), thyroparathyroidectomized rats challenged with PTH or $1 \alpha, 25-$ $(\mathrm{OH})_{2} \mathrm{D}_{3}(35)$, and mice with humoral hypercalcemia of malignancy $(34,36)$ rapidly lowered serum calcium levels. Radiographic and histomorphometric analysis of OPG-L/ODF-treated mice (3 days of treatment) demonstrated a dose-related profound bone loss associated with the presence of larger and higher nucleated mature OC and doubling of the OC area while the number of $\mathrm{OC}$ was not changed (10).

Of interest, the formation of osteoclasts in mice following administration of soluble OPG-L/ODF was limited to bone, although other tissues also produce significant concentrations of M-CSF (10). This finding suggests that intrinsic factors (bone matrix proteins, adhesion molecules, and others) may be produced in the bone/bone marrow microenvironment that facilitate osteoclastogensis.

Effects of OPG-L/ODF on immune function As noted earlier, the OPG-L/ODF was initially identified as TRANCE (46) or RANKL (47) and was demonstrated to have important effects on immune function. RANKL 
induced cluster formation by DC and stimulated allostimulatory capacity of DC on T cells as well as cytokine-activated T cell growth (47). TRANCE, initially identified as an immediate early gene upon $\mathrm{T}$ cell receptor activation, induced c-Jun $\mathrm{N}$-terminal kinase (JNK) activation in $\mathrm{T}$ cells, but not B cells (46). Subsequent studies demonstrated that TRANCE binds to high-affinity sites located on the surface of mature DC (56). TRANCE inhibited apoptosis of both bone marrowand monocyte-derived DC, thus increasing DC survival, possibly by increasing the expression of the antiapoptotic gene $\mathrm{Bcl}-\mathrm{x}_{\mathrm{L}}$, while it had no effect on the proliferation or survival of $\mathrm{T}$ or $\mathrm{B}$ cells (56). These studies demonstrate that TRANCE/RANKL, in addition to its important role in osteoclastogenesis, represents a paracrine mediator for the communication between $\mathrm{T}$ cells and DC. Moreover, the two receptors of OPG-L/ODF, osteoclast differentiation and activation receptor (ODAR)/receptor activator of NF- $\kappa \mathrm{B}$ (RANK) (47) and OPG/OCIF (16), are up-regulated by CD40 stimulation in immune cells. These data suggest that TRANCE/ RANKL may act as a pleiotropic cytokine within the bone marrow microenvironment to regulate the immune system and bone metabolism.

\section{Regulation of OPG-L/ODF expression}

Hormones and cytokines that modulate the production of OPG-L/ODF (Table 3) are likely to be major regulators of osteoclastogenesis, because OPG-L/ODF (in combination with M-CSF) is both necessary and sufficient to induce osteoclastogenesis, and replaces the need for coculture with stromal cells or the presence of conditioned medium from stromal or osteoblastic cells. Among the factors that up-regulate OPG-L/ODF mRNA steady-state levels in marrow stromal and osteoblastic cells are dexamethasone, $1 \alpha, 25-(\mathrm{OH})_{2} \mathrm{D}_{3}$, IL-11, PTH, and PGE 2 $(11,23,39)$. In addition, the pro-inflammatory cytokines IL- $1 \beta$ and TNF- $\alpha$ have recently been demonstrated to stimulate OPG-L/ODF mRNA steady-state levels in primary and immortalized marrow stromal cells and the osteosarcoma cell line MG-63 (48). The concept that some of the bone-resorbing hormones and cytokines regulate bone resorption indirectly by increasing the production of OPG-L/ODF is further supported by a recent study by Tsukii et al. (30). While OPG-L/ODF dosedependently stimulated bone resorption in a fetal mouse long bone culture system as assessed by ${ }^{45} \mathrm{Ca}$ release, bone resorption induced by $1 \alpha, 25-(\mathrm{OH})_{2} \mathrm{D}_{3}, \mathrm{PTH}, \mathrm{PGE}_{2}$, and IL- $1 \alpha$ was prevented by co-treatment with OPG/ OCIF and by OPG-L/ODF neutralizing antibodies (30). By contrast, Takai et al. (44) showed that TGF- $\beta$ suppressed OPG-L/ODF mRNA steady-state levels (and concurrently stimulated OPG/OCIF mRNA levels) by murine stromal cells (ST-2) (Table 3) which resulted in an inhibition of osteoclastogenesis.

\section{Receptor for OPG-L/ODF}

\section{Identificationandorganization of ODAR/RANK}

The receptor for OPG-L/RANKL, RANK, was identified by Anderson et al. (47). The human RANK is a polypeptide of 616 amino acids and belongs to the type I transmembrane protein class. RANK mapped to the human chromosome 18q22.1 (47). Its hydropathy analysis predicts a signal peptide of 28 amino acids, an N-terminal extracellular domain of 184 amino acids, a short transmembrane domain of 21 amino acids and a large C-terminal cytoplasmic domain of 383 amino acids (47). Similar to OPG, the extracellular domain of RANK contains four cysteine-rich pseudorepeats and two N-glycosylation sites $(47,57)$. The human RANK is $70 \%$ homologous to the murine RANK (47) and when compared with other TNFR family members is $40 \%$ identical to CD40 (47). More recently, Hsu and colleagues (58) characterized RANK which they named ODAR (58).

Table 3 Regulation of OPG-L/ODF

\begin{tabular}{llc}
\hline Stimulation & \multicolumn{1}{c}{ Cells } & Reference \\
\hline Dexamethasone & Primary marrow stromal cells & $(23)$ \\
& hFOB & $(23)$ \\
$1 \alpha, 25-(\mathrm{OH})_{2} \mathrm{D}_{3}$ & Primary murine osteoblasts ST-2, tsJ2 cells, KUSA/O & $(11,39)$ \\
$\mathrm{IL}-1 \beta$ & Primary human marrow stromal cells, hMS, MG-63 cells & $(48)$ \\
$\mathrm{IL}-11$ & Primary murine osteoblasts & $(11,39)$ \\
$\mathrm{PTH}$ & Primary murine osteoblasts & $(11,39)$ \\
$\mathrm{PGE}$ & & $(11)$ \\
$\mathrm{TNF} \alpha$ & Primary mouse calvaria cells & $(48)$ \\
\hline Inhibition & Primary human marrow stromal cells, hMS, MG-63 cells & \\
\hline TGF- $\beta$ & & $(44)$ \\
\hline
\end{tabular}

Abbreviations: ST-2, tsJ2, and KUSA/O, murine marrow stromal cell lines; hMS, human marrow stromal cell line, hFOB, human fetal osteoblastic cell line. 


\section{Expression and regulation of ODAR/RANK}

ODAR/RANK mRNA is expressed in many tissues, including skeletal muscle, liver, small intestine and colon, thymus and adrenal gland (47). In addition to OC $(58,59)$, ODAR/RANK mRNA is expressed in various lymphocytic and non-lymphocytic cell lines (47). The most abundant ODAR/RANK mRNA species is a $4.5 \mathrm{~kb}$ mRNA fragment in humans (47) and a $5.5 \mathrm{~kb}$ mRNA fragment in mice (59); however, there are additional ODAR/RANK mRNA species $(3.0 \mathrm{~kb}, 3.5 \mathrm{~kb})$ as a result of alternative polyadenylation signals. Although ODAR/ RANK mRNA is expressed in various cell systems, the expression of ODAR/RANK protein is restricted to OC, DC, B and T cell lines, and fibroblasts (47), suggesting that ODAR/RANK expression may be post-transcriptionally regulated $(46,47)$. Among bone cells, ODAR/ RANK mRNA is exclusively expressed in OC precursor cells isolated by FACS analysis using fluorescein labeled OPG-L/ODF (58). Regulation of ODAR/RANK expression in OC has not been studied. In immune cells, ODAR/RANK on the surface of T cells is up-regulated by IL- 4 and TGF- $\beta$ (47), while CD40 ligand induces the expression of ODAR/RANK on DC (47).

\section{Biological effects of ODAR/RANK}

Two studies have established that OPG-L/ODF binds specifically and with high affinity to ODAR/RANK located on osteoclastic lineage cells, and that activation of ODAR/RANK by OPG-L/ODF is necessary and sufficient for osteoclastogensis $(58,59)$. Of interest, transgenic mice overexpressing soluble ODAR/RANK-Fc fusion protein (which acts as a neutralizing receptor for OPG-L/ODF) had osteopetrosis, similar to transgenic mice overexpressing OPG/OCIF (58). Consistent with this, administration of soluble ODAR/RANK-Fc fusion proteins blocked OC differentiation and activation in vivo (58) and in vitro $(58,59)$ similar to the effects of OPG/OCIF.

In an elegant study, Nakagawa et al. (59) employed two different RANK antibodies, a polyvalent divalent antibody (ODAR/RANK-Ab) and a monovalent version of ODAR/RANK-Ab (Fab-RANK). While the ODAR/ RANK-Ab which is able to cross-link and cluster antigens mimicked OPG-L/ODF action and stimulated osteoclastogenesis, the monovalent Fab-RANK which lacks the ability to cross-link and to cluster antigens behaved as an OPG-L/ODF antagonist and inhibited osteoclastogenesis (59). This study suggests that the clustering of ODAR/RANK is required for ODAR/RANK activation during osteoclastogenesis (59).

\section{Signal transduction of ODAR/RANK}

Anderson et al. (47) were the first to report that ODAR/ RANK overexpression is sufficient to activate NF- $\kappa$ B. Several recent studies have since provided important insights into the intracellular signal transduction following activation of the ODAR/RANK $(47,58)$. ODAR/RANK interacts with TNFR-associated factor (TRAF) family members to activate the transcriptional factor NF- $\kappa \mathrm{B}$ and the protein kinase JNK $(47,57,60)$. TRAFs constitute a family of six cytoplasmic adapter proteins which contain zinc fingers and are known to regulate cell survival, proliferation, and apoptosis by activating NF- $\kappa \mathrm{B}$ and other transcriptional factors (61). The intracellular domain of the human ODAR/RANK contains three putative TRAF-binding domains which strongly bind TRAF1, TRAF2, TRAF3, and TRAF6, and weakly bind TRAF5 $(57,60,62)$.

Functional analysis of the human ODAR/RANK revealed that the $\mathrm{C}$-terminal 85 amino acids which bind TRAF2, TRAF5, and TRAF6 are essential for NF$\kappa \mathrm{B}$ activation (57). In a similar manner, the C-terminal 93 amino acids which bind TRAF2, TRAF5, and TRAF6 are essential for the murine $\operatorname{ODAR} / \operatorname{RANK}(60,62)$. Recent studies suggest that NF- $\kappa$ B and JNK activation by ODAR/RANK are differentially regulated by TRAFs ( 56 , 57, 60, 62, 63). Interestingly, ODAR/RANK-induced JNK and NF- $\kappa$ B activation are induced in cells overexpressing TRAF2, TRAF5, and TRAF6 (63), while NF$\kappa \mathrm{B}$ activation is suppressed in cells with dominant negative forms of TRAF2, TRAF5, and TRAF6 (60). A TRAF6-binding site (amino acids 340-421) appears to be specifically essential for NF- $\kappa$ B, but not for JNK activation (62). Similarly, an intact zinc finger of the TRAFs is required only for NF- $\kappa \mathrm{B}$ (63). Of note, TRAF2 has been reported to be a gene target of $N F-\kappa B$ transcriptional activity (64). The most compelling evidence for the TRAF proteins as regulators of osteoclast function was recently derived from the generation of TRAF6-deficient mice which had osteopetrosis and impaired tooth eruption (65). At the cellular level, osteoclasts from these TRAF6 knock-out mice failed to form ruffled borders, suggesting an essential role for TRAF6 in osteoclast activation (65).

\section{New basic science and clinical implications}

\section{OPG-L/OPG and the cytokine network}

Genetic manipulation of the OPG-L/OPG system resulted in both extremes of skeletal phenotype. Both targeted ablation of OPG-L/ODF in knock-out mice (51) and overexpression of OPG/OCIF in transgenic mice (8) resulted in impaired osteoclastogenesis and osteopetrosis, while both the administration of OPG-L/ODF (10) and targeted ablation of OPG/OCIF in knock-out mice $(25,26)$ resulted in enhanced osteoclastogenesis and severe osteoporosis (Table 4). Because of these phenotypes, and because OPG-L/ODF, in the presence of MCSF, is necessary and sufficient for osteoclastogenesis, and OPG/OCIF represents its endogenous antagonist (Fig. 1), it has been suggested that the interactive network of bone-resorbing and anti-resorptive cytokines 
Table 4 Skeletal phenotypes associated with alterations of the OPG-L/ODF-OPG/OCIF system

\begin{tabular}{lllr}
\hline Phenotype & \multicolumn{1}{c}{ Intervention } & \multicolumn{1}{c}{ Other abnormalities } & Reference \\
\hline Osteoporosis & OPG/OCIF knock-out & Arterial calcification & $(25)$ \\
& & - & $(26)$ \\
Osteopetrosis & OPG-L/ODF administration & Hypercalcemia & $(11)$ \\
& OPG/OCIF overexpression & Extramedullary hematopoiesis & $(8)$ \\
& OPG/OCIF administration & - Extramedullary hematopoiesis, delayed & $(51)$ \\
& OPG-L/ODF knock-out & tooth eruption, short, flat bones, defects & $(58)$ \\
& & in B and T cell maturation & $(65)$ \\
& sODAR overexpression & - & Delayed tooth eruption, hypophosphatemia, \\
& TRAF6 knock-out & defects in IL-1, CD40 and lipopolysaccharide & \\
& & signaling & \\
\hline
\end{tabular}

SODAR, soluble osteoclast differentiation and activation receptor.

and hormones converges at the levels of the OPG-L/OPG system (Fig. 2). OPG-L/OPG would then serve as the final common effector system to regulate the formation of OC from precursors in the bone marrow and its subsequent activation. Thus, the various calcitropic cytokines and hormones would indirectly regulate bone resorption by regulating either OPG-L/ODF or OPG/ OCIF, or both (Fig. 2). In support of this concept are the findings that bone resorption induced by $1 \alpha, 25-$ $(\mathrm{OH})_{2} \mathrm{D}_{3}, \mathrm{PTH}, \mathrm{PGE}_{2}$, and IL- $1 \alpha$ was prevented in a fetal mouse long bone culture system by OPG/OCIF and by OPG-L/ODF-neutralizing antibody (30). Moreover, IL-1 and TNF up-regulate OPG-L/ODF gene expression (48) and OPG/OCIF production $(21,37,38)$, the latter of which may represent a counter-regulatory protective mechanism. Conceptually, convergence of various calcitropic cytokines, peptide and steroid hormones to two final effectors of osteoclast formation and activation, OPG-L/ODF and OPG/OCIF, may provide a highly efficient and balanced regulatory mechanism of bone resorption.

Of note, IL-6, a cytokine implicated in bone loss associated with sex hormone deficiency (5-7), has no effect on the OPG-L/OPG system $(21,37,38)$. In fact, a recent study indicated that $\mathrm{IL}-6$ may regulate osteoclastogenesis independent of OPG-L/ODF (66). In mice with targeted ablation of $\mathrm{NF}-\kappa \mathrm{B} 1$ and $\mathrm{NF}-\kappa \mathrm{B} 2$, transcription factors required for OPG-L/ODF signaling, no osteoclastogenesis occurred in cultured spleen cells following treatment with OPG-L/ODF, M-CSF, IL- $1 \beta$, and TNF- $\alpha$, suggesting that both OPG-L/ODF and NF- $\kappa$ B are essential for osteoclastogenesis. However, IL-6 in the presence of IL- 6 soluble receptor induced OC formation in the NF- $\kappa$ B double knock-out mice ( $6 \%$ of that induced by OPG-L/ODF in wild-type mice), indicating an OPG-L/ ODF-independent signaling pathway (66).

Thus, osteoclastogenesis appears to be regulated by two parallel pathways, a major NF- $\kappa$ B-dependent
Figure 2 Balance of osteoclast differentiation and activation by OPG-L/ODF and OPG/OCIF. Regulation by hormones and cytokines. $17 \beta$ - $\mathrm{E}_{2}, 17 \beta$-estradiol.

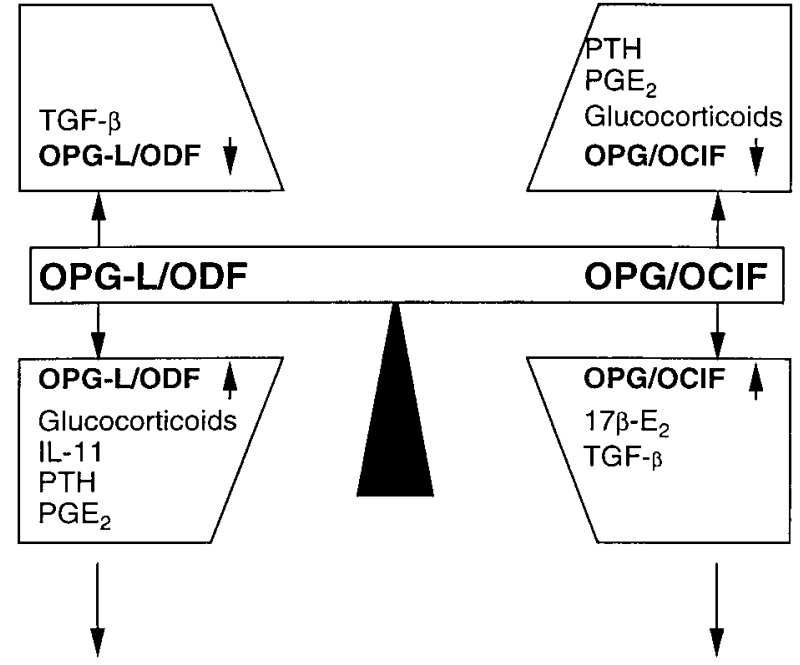

Increased osteoclastic bone resorption
Decreased osteoclastic bone resorption 
pathway which requires OPG-L/M-CSF and ODAR/ RANK activation, and a minor NF- $\kappa \mathrm{B}$-independent pathway which involves IL-6 and gp130 activation. Both systems may be differentially modulated by factors.

\section{OPG-L/OPG and estrogen deficiency}

Postmenopausal osteoporosis is associated with increased osteoclastogenesis and bone resorption which results in rapid bone loss within the first 4 to 8 years after menopause (67). A stimulation of the production and action of proinflammatory and boneresorbing cytokines (IL-1, TNF- $\alpha$, IL-6) by bone marrow stromal cells and osteoblasts elicited by estrogen deficiency has been previously suggested as a major mechanism of postmenopausal osteoporosis (5-7).

Recent studies have shown that estrogen (24) and TGF- $\beta(40,44)$, a peptide growth factor which is induced in osteoblastic cells by estrogen (68), increases the production of OPG/OCIF by osteoblasts and stromal cells respectively. TGF- $\beta$ concurrently also decreases OPG-L/ODF mRNA expression by stromal cells, and these effects are associated with an inhibiton of osteoclastogenesis (44). A previous study has suggested that the effects of estrogen on apoptosis of murine OC are mediated by TGF- $\beta$ (69). These data indicate that estrogen may act by increasing OPG/OCIF which then would neutralize the OPG-L/ODF and prevent it from stimulating osteoclastogenesis, and these effects may be potentiated by increased production of TGF- $\beta$ (Fig. 2). Whether estrogen also regulates the production of the OPG-L/ODF production is not known.

Recently, Yano et al. (70) reported a threefold increase in serum OPG/OCIF levels with aging in humans and a small increase in osteoporotic compared with agematched non-osteoporotic postmenopausal women, and hypothesized that these increases reflect a compensatory response to the increase in bone resorption. In contrast, Arrighi et al. (71) failed to find major increases in serum levels of OPG/OCIF with age in a large cohort of women. Further studies are needed to examine these controversial issues in more detail.

Although prevention of bone loss in oophorectomized rats has also been reported when other candidate cytokines such as IL-1 $\beta$, TNF- $\alpha$, and IL-6 were antagonized or neutralized (5-7), the OPG-L/OPG system is unique. In contrast to other candidate cytokines, OPG/OCIF prevented bone loss when administered to oophorectomized rats (8) and resulted in both phenotypic extremes of osteopetrosis (OPG/OCIF overexpression) (8) or (OPG-L/ODF deletion) (51), and osteoporosis (OPG/OCIF deletion) $(25,26)$.

Finally, in further support of the OPG-L/OPG/M-CSF system as the mediator of the anti-resorptive effects of estrogen on bone are the findings that the production of the permissive factor M-CSF by human bone marrow cultures is suppressed by estrogen (72), and that estrogen deficicency induced by ovariectomy results in an increased production of M-CSF (73).

\section{OPG-L/OPG and glucocorticoid excess}

Glucocorticoid-induced osteoporosis represents the most common form of secondary osteoporosis and is a serious complication of systemic glucocorticoid use (74, 75). It is generally accepted that glucocorticoids decrease bone formation (74-77) and increase bone resorption in vitro $(78-80)$ as well as in vivo (81-83). Recent studies have clearly identified the OPG-L/OPG system as a potential glucocorticoid target and potential mediator for the detrimental skeletal effects of glucocorticoids $(22,23)$. In these two studies, glucocorticoids are the single most potent inhibitors of OPG/OCIF production (by up to $90 \%$ ) by various human osteoblastic cell systems regardless of their stage of differentiation, phenotype, and absolute OPG/OCIF mRNA steady levels $(22,23)$. Dexamethasone also decreased OPG/OCIF mRNA levels in the murine stromal cell line, ST-2, while it had a biphasic effect with an initial decrease and a subsequent increase in primary murine osteoblasts (40). Concurrently, glucocorticoids also stimulated OPG-L/ODF mRNA steady levels by two- to fourfold (23) and enhanced the stimulatory effect of $1 \alpha, 25-(\mathrm{OH})_{2} \mathrm{D}_{3}$ on OPG-L/ODF mRNA steady levels (11). Thus, glucocorticoids markedly increased the relative OPG-L/OPG ratio in human osteoblastic cell systems (Fig. 2), which could explain the rapid and severe bone loss following initiation of systemic glucocorticoid therapy $(74,75)$.

\section{OPG-L/OPG and osteopetrosis}

Osteopetrosis is a rare polygenic disorder of bone metabolism characterized by a generalized increase of bone mass due to decreased osteoclastogenesis and bone resorption (84). The mechanisms underlying its pathogenesis have obvious implications for the understanding of the development of metabolic bone diseases. In view of the new paradigm of osteoclastogenesis in which OPG-L/ODF, OPG/OCIF and M-CSF are key determinants, the pathogenesis of osteopetrosis can be revisited.

Blocking of the actions of OPG-L/ODF by overexpression of the neutralizing receptor OPG/OCIF results in osteopetrosis (8). In addition, OPG-L/ODF knock-out mice (51) and transgenic mice overexpressing the soluble ODAR/RANK (58) also have osteopetrosis. Moreover, mice lacking both forms of the transcription factors $\mathrm{NF}-\kappa \mathrm{B} 1$ and $\mathrm{NF}-\kappa \mathrm{B} 2$, which are involved in intracellular signaling by ODAR/RANK (47), also have osteopetrosis (85). Consistent with this are the findings in NF- $\kappa \mathrm{B} 1$ - and NF- $\kappa \mathrm{B} 2$-deficient mice, in which OPG-L/ ODF and M-CSF failed to induce osteoclastogenesis (66). Osteopetrosis is also present in mice with a deficiency of TRAF6, an intracellular adapter protein activated by ODAR/RANK (65). In addition, a mutation in the 
coding region of the M-CSF gene which leads to the absence of M-CSF protein has been detected in the op/op mouse, a murine model of spontaneous osteopetrosis, which can be corrected by exogenous administration of M-CSF (86). These data collectively indicate that various forms of experimental models of osteopetrosis can be attributed to disruption of the production, action, intracellular signal pathway, or nuclear activation of either OPG-L/ODF or M-CSF. These different defects ultimately converge at the level of OC differentiation and/or activation and lead to impaired bone resorption.

\section{OPG-L/OPG and other metabolic bone diseases}

Other important metabolic bone diseases in which the OPG-L/OPG system may be involved in mediating increased bone resorption or in which exogenous administration of OPG/OCIF may be potentially useful include humoral hypercalcemia of malignancy, rheumatoid arthritis, and primary hyperparathyroidism. The hypocalcemic effect of OPG/OCIF has been demonstrated in various animal models, including normocalcemic animals $(17,36)$ and hypercalcemic animals due to treatment with OPG-L/ODF (10), IL-1 (34), thyroparathyroidectomy and subsequent challenge with PTH and $1 \alpha, 25-(\mathrm{OH})_{2} \mathrm{D}_{3}(35)$, and nude mice with humoral hypercalcemia of malignancy $(34,36)$. In these studies, administration of OPG/OCIF had a rapid onset, profound, and dose-dependent hypocalcemic effect, was well tolerated and had no adverse extraskeletal effects. Thus, the administration of recombinant OPG/OCIF may be a useful tool in the treatment of severe hypercalcemia in the clinical setting.

Recently, activated CD4+ helper cells were found to produce OPG-L/ODF in the presence of proinflammatory cytokines (87). Since CD4+ helper cells also account for the majority of inflammatory cells infiltrating the synovium in rheumatoid arthritis, abnormal OPG-L/ ODF production may also be involved in the pathogenesis of periarticular bone loss adjacent to affected joints in rheumatoid arthritis (87). Interestingly, OPG/OCIF levels in the synovial fluid are lower in patients with rheumatoid arthritis than in patients with other forms of arthropathy (gout, osteoarthritis, trauma) (88). Thus, the combination of increased OPG-L/ODF production by inflammatory cells and the decreased OPG/OCIF production may contribute to the increased periarticular bone resorption in patients with rheumatoid arthritis.

Finally, the observations that PTH increased OPG-L/ ODF mRNA levels $(11,33,39)$ and decreased OPG/OCIF mRNA levels (40) in osteoblastic cells, thus increasing the OPG-L/OPG ratio (39), suggest that the OPG-L/OPG system may also contribute to the increased bone loss in primary hyperparathyroidism. Clearly, additional studies are required to directly assess the role of the OPG-L/ OPG system as a paracrine mediator of bone resorption in hyperparathyroidism.

\section{Conclusions}

Enhanced osteoclastogenesis is a hallmark of various forms of osteoporosis. The recent discovery of OPG-L/ ODF has led to a paradigmatic shift of osteoclastogenesis. Based on extensive studies, it has become clear that OPG-L/ODF (in the presence of M-CSF) is the essential cytokine for osteoclastogenesis, and that no other cytokines are required. OPG-L/ODF is produced by marrow stromal cells and osteoblasts, and stimulates the differentiation and activation of OC by binding to its high-affinity receptor, ODAR/RANK located on the surface of OC and activating NF- $\kappa$ B. The bone-resorbing effects of OPG-L/ODF are physiologically counterbalanced by the endogenous, naturally occurring soluble receptor OPG/OCIF which competes with ODAR/RANK for OPG-L/ODF. Most of the calcitropic cytokines, peptide and steroid hormones have been shown to regulate the expression of OPG-L/ODF or OPG/OCIF, or both, indicating a gatekeeping and integrating function of these two factors (Fig. 2). Importantly, some of the commonly used therapeutic agents (glucocorticoids, estrogen, PTH, $\left.1 \alpha, 25-(\mathrm{OH})_{2} \mathrm{D}_{3}\right)$ differentially modulate the production of OPG-L and/or OPG/OCIF. These discoveries raise the hope that therapeutic strategies aimed at decreasing the OPG-L/ODF to OPG/OCIF ratio may suppress osteoclast formation and activation, and prevent bone loss. In light of the recent accumulation of synonyms (Table 1), a revised unitary nomenclature for the components of this cytokine system appears to be mandatory.

\section{Acknowledgements}

The author's research was supported by a postdoctoral fellowship grant from the Deutsche Forschungsgemeinschaft (Ho 1875/1-1 and 2-1).

\section{References}

1 Suda T, Takahashi N \& Martin TJ. Modulation of osteoclast differentiation. Endocrine Reviews 199213 66-80.

2 Suda T, Nakamura I, Jimi E \& Takahashi N. Regulation of osteoclast function. Journal of Bone and Mineral Research 199712 869-879.

3 Roodman GR. Advances in bone biology: the osteoclast. Endocrine Reviews 199617 308-332.

4 Reddy SV \& Roodman GD. Control of osteoclast differentiaton. Critical Reviews in Eukaryotic Gene Expression 19988 1-17.

5 Pacifici R. Estrogen, cytokines, and pathogenesis of postmenopausal osteoporosis. Journal of Bone and Mineral Research 199611 1043-1051.

6 Manolagas SC \& Jilka RL. Bone marrow, cytokines, and bone remodeling: emerging insights into the pathophysiology of osteoporosis. New England Journal of Medicine 1995332 305311.

7 Jilka RL. Cytokines, bone remodeling, and estrogen deficiency: a 1998 update. Bone 199823 75-81.

8 Simonet WS, Lacey DL, Dunstan CR, Kelley M, Chang M-S, Lüthy $\mathrm{R}$ et al. Osteoprotegerin: a novel secreted protein involved in the regulation of bone density. Cell 199789 309-319. 
9 Yasuda H, Shima N, Nakagawa N, Mochizuki S-I, Yano K, Fujise N et al. Identity of osteoclastogenesis inhibitory factor (OCIF) and osteoprotegerin (OPG): a mechanism by which OPG/OCIF inhibits osteoclastogenesis in vitro. Endocrinology 1998139 1329-1337.

10 Lacey DL, Timms E, Tan H-L, Kelley MJ, Dunstan CR, Burgess T et al. Osteoprotegerin (OPG) ligand is a cytokine that regulates osteoclast differentiation and activation. Cell 199893 165-176.

11 Yasuda H, Shima N, Nakagawa N, Yamaguchi K, Kinosaki M, Mochizuki S-I et al. Osteoclast differentiation factor is a ligand for osteoprotegerin/osteoclastogenesis-inhibitory factor and is identical to TRANCE/RANKL. Proceedings of the National Academy of Sciences of the USA 199895 3597-3602.

12 Orlinick JR \& Chao MV. TNF-related ligands and their receptors. Cellular Signalling 199810 543-551.

13 Tan KB, Harrop J, Reddy M, Young P, Terrett J, Emery J et al. Characterization of a novel TNF-like ligand and recently described TNF ligand and TNF receptor superfamily genes and their constitutive and inducible expression in hematopoietic and nonhematopoietic cells. Gene 1997204 35-46.

14 Kwon BS, Wang S, Udagawa N, Haridas V, Lee ZH, Kim KK et al. TR1, a new member of the tumor necrosis factor receptor family, induces fibroblast proliferation and inhibits osteoclastogenesis and bone resorption. FASEB Journal 199812 845-854.

15 Tsuda E, Goto M, Mochizuki S-I, Yano K, Kobayashi F, Morinaga T et al. Isolation of a novel cytokine from human fibroblasts that specifically inhibits osteoclastogenesis. Biochemical and Biophysical Research Communications 1997234 137-142.

16 Yun TJ, Chaudhary PM, Shu GL, Frazer JK, Ewings MK, Schwartz SM et al. OPG/FDCR-1, a TNF receptor family member, is expressed in lymphoid cells and is up-regulated by ligating CD40. Journal of Immunology 1998161 6113-6121.

17 Tomoyasu A, Goto M, Fujise N, Mochizuki S, Yasuda H, Morinaga $\mathrm{T}$ et al. Characterization of monomeric and homodimeric forms of osteoclastogenesis inhibitory factor. Biochemical and Biophysical Research Communications 1998245 382-387.

18 Yamaguchi K, Kinosaki M, Goto M, Koboyashi F, Tsuda E, Morinaga $\mathrm{T}$ et al. Characterization of structural domains of human osteoclastogenesis inhibitory factor. Journal of Biological Chemistry 1998273 5117-5123.

19 Morinaga T, Nakagawa N, Yasuda H, Tsuda E \& Higashio K. Cloning and characterization of the gene encoding human osteoprotegerin/osteoclastogenesis-inhibitory factor. European Journal of Biochemistry 1998254 685-691.

20 Mizuno A, Murakami A, Nakagawa N, Yasuda H, Tsuda E, Morinaga $\mathrm{T}$ et al. Structure of the mouse osteoclastogenesis inhibitory factor/osteoprotegerin gene and its expression in embryogenesis. Gene 1998215 339-343.

21 Hofbauer LC, Dunstan CR, Spelsberg TC, Riggs BL \& Khosla S. Osteoprotegerin production by human osteoblast lineage cells is stimulated by vitamin D, bone morphogenetic protein-2, and cytokines. Biochemical and Biophysical Research Communications $1998250776-781$.

22 Vidal NOA, Brändström H, Jonsson KB \& Ohlsson C. Osteoprotegerin mRNA is expressed in primary human osteoblast-like cells: down-regulation by glucocorticoids. Journal of Endocrinology $1998159191-195$.

23 Hofbauer LC, Gori F, Riggs BL, Dunstan CR, Lacey DL, Spelsberg TC \& Khosla S. Stimulation of osteoprotegerin ligand and inhibition of osteoprotegerin production by glucocorticoids in human osteoblastic lineage cells: Potential paracrine mechanisms of glucocorticoid-induced osteoporosis. Endocrinology 1999 (In Press).

24 Hofbauer LC, Khosla S, Dunstan CR, Spelsberg TC \& Riggs BL. Estrogen stimulates production of the anti-resorptive cytokine receptor osteoprotegerin in human osteoblastic cells. Endocrinology 1999 (In Press).

25 Bucay N, Sarosi I, Dunstan CR, Morony S, Tarpley J, Capparelli C et al. Osteoprotegerin-deficient mice develop early onset osteoporosis and arterial calcification. Genes and Development 199812 $1260-1268$.
26 Mizuno A, Amizuka N, Irie K, Murakami A, Fujise N, Kanno T et al. Severe osteoporosis in mice lacking osteoclastogenesis inhibitory factor/osteoprotegerin. Biochemical and Biophysical Research Communications 1998247 610-615.

27 Miyamoto A, Kunisada T, Hemmi H, Yamane T, Yasuda H, Miyake $\mathrm{K}$ et al. Establishment and characterization of an immortal macrophage-like cell line inducible to differentiate to osteoclasts. Biochemical and Biophysical Research Communications 1998242 703-709.

28 Emery JG, McDonnell P, Brigham Burke M, Deen KC, Lyn S, Silverman $\mathrm{C}$ et al. Osteoprotegerin is a receptor for the cytotoxic ligand TRAIL. Journal of Biological Chemistry 1998273 1436314367.

29 Tan H-L, Van G, Scully S, Shimamoto G, Kelley M, Boyle B et al. Recombinant osteoprotegerin (OPG), a novel TNF-receptor family member, inhibits in vitro murine osteoclast formation from bone marrow precursors. Journal of Bone and Mineral Research 199712 (Suppl 1) S155 (Abstract no. P213).

30 Tsukii N, Shima N, Mochizuki S, Yamaguchi K, Kinosaki M, Yano $\mathrm{K}$ et al. Osteoclast differentiation factor mediates an essential

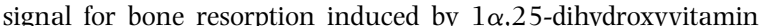
$\mathrm{D}_{3}$, prostaglandin $\mathrm{E}_{2}$, or parathyroid hormone in the microenvironment of bone. Biochemical and Biophysical Research Communications 1998246 337-341.

31 Hakeda Y, Kobayashi Y, Yamaguchi K, Yasuda H, Tsuda E, Higashio $\mathrm{K}$ et al. Osteoclastogenesis inhibitory factor (OCIF) directly inhibits bone-resorbing activity of isolated mature osteoclasts. Biochemical and Biophysical Research Communications $1998251796-801$

32 Akatsu T, Murakami T, Nishikawa M, Ono K, Shinomiya N, Tsuda E et al. Osteoclastogenesis-inhibitory factor suppresses osteoclast survival by interfering in the interaction of stromal cells with osteoclast. Biochemical and Biophysical Research Communications $1998250229-234$.

33 Fuller K, Wong B, Fox S, Choi Y \& Chambers TJ. TRANCE is necessary and sufficient for osteoblast-mediated activation of bone resorption in osteoclasts. Journal of Experimental Medicine 1998188 997-1001.

34 Dunstan CR, Capparelli C, Kelley M, Shimamoto G, Kaufman S, Russell D et al. Osteoprotegerin (OPG), a novel TNF-receptor family member, profoundly inhibits endosteal bone resorption due to growth, humoral hypercalcemia of malignancy, and interleukin 1. Journal of Bone and Mineral Research 199712 (Suppl 1) S136 (Abstract no. 134).

35 Yamamoto M, Murakami T, Nishikawa M, Tsuda E, Mochizuki S-I, Higashio $\mathrm{K}$ et al. Hypocalcemic effect of osteoclastogenesis inhibitory factor/osteoprotegerin in the thyroparathyroidectomized rat. Endocrinology $19981394012-4015$.

36 Akatsu T, Murakami T, Ono K, Nishikawa M. Tsuda E, Mochizuki S-I et al. Osteoclastogenesis inhibitory factor exhibits hypocalcemic effects in normal mice and in hypercalcemic nude mice carrying tumors associated with humoral hypercalcemia of malignancy. Bone 199823 495-498.

37 Vidal ONA, Sjögren K, Eriksson BI, Ljunggren Ö \& Ohlsson C. Osteoprotegerin mRNA is increased by interleukin- $\alpha$ in the human osteosarcoma cell line MG-63 and in human osteoblastlike cells. Biochemical and Biophysical Research Communications 1998248 696-700.

38 Brändström $\mathrm{H}$, Jonsson $\mathrm{KB}$, Vidal $\mathrm{O}$, Ljunghall, Ohlsson C \&

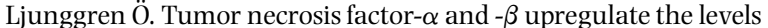
of osteoprotegerin mRNA in human osteosarcoma MG-63 cells. Biochemical and Biophysical Research Communications 1998248 454-457.

39 Horwood NJ, Elliott J, Martin TJ \& Gillespie MT. Osteotropic agents regulate the expression of osteoclast differentiation factor and osteoprotegerin in osteoblastic stromal cells. Endocrinology 1998 139 4743-4746.

40 Murakami T, Yamamoto M, Yamamoto M, Ono K, Nishikawa M, Nagata $\mathrm{N}$ et al. Transforming growth factor- $\beta 1$ increases mRNA levels of osteoclastogenesis inhibitory factor in osteoblastic/ 
stromal cells and inhibits the survival of murine osteoclast-like cells. Biochemical and Biophysical Research Communications 1998 $252747-752$

41 Spinas GA, Keller U \& Brockhaus M. Release of soluble receptors for tumor necrosis factor (TNF) in relation to circulating TNF during experimental endotoxinemia. Journal of Clinical Investigation $199290533-536$.

42 Chenu C, Pfeilschifter J, Mundy GR \& Roodman GD. Transforming growth factor beta inhibits formation of osteoclast-like cells in long-term human marrow cultures. Proceedings of the National Academy of Sciences of the USA 198885 5683-5687.

43 Pfeilschifter J, Seyedin SM \& Mundy GR. Transforming growth factor beta inhibits bone resorption in fetal rat long bone cultures. Journal of Clinical Investigation 198882 680-685.

44 Takai H, Kanematsu M, Yano K, Tsuda E, Higashio K, Ikeda K et al. Transforming growth factor- $\beta$ stimulates the production of osteoprotegerin/osteoclastogenesis inhibitory factor by bone marrow stromal cells. Journal of Biological Chemistry 1998273 27091-27096.

45 Brändström H, Jonsson KB, Ohlsson C, Vidal O, Ljunghall S \& Ljunggren Ö. Regulation of osteoprotegerin mRNA levels by prostaglandin $\mathrm{E}_{2}$ in human bone marrow stroma cells. Biochemical and Biophysical Research Communications 1998247 338-341.

46 Wong BR, Rho J, Arron J, Robinson E, Orlinick J, Chao M et al. TRANCE is a novel ligand of the tumor necrosis factor receptor family that activates c-jun N-terminal kinase in T cells. Journal of Biological Chemistry 1997272 25190-25194.

47 Anderson MA, Maraskovsky E, Billingsley WL, Dougall WC, Tometsko ME, Roux ER et al. A homologue of the TNF receptor and its ligand enhance T-cell growth and dendritic-cell function. Nature 1997390 175-179.

48 Hofbauer LC, Lacey DL, Dunstan CR, Spelsberg TC, Riggs BL \& Khosla S. Interleukin- $\beta$ and tumor necrosis factor- $\alpha$, but not interleukin-6 stimulate osteoprotegerin ligand mRNA levels in human osteoblastic cells. Bone 199924 (In Press).

49 O'Brien CA, Farrar NC \& Manolagas SC. Identification of an OSF-2 binding site in the murine RANKL/OPGL gene promoter: a potential link between osteoblastogenesis and osteoclastogenesis. Bone 199823 (Suppl 1) S149 (Abstract no. 1003).

50 Gao Y-H, Shinki T, Yuase T, Kataoka-Enomoto H, Komori T, Suda T et al. Potential role of cbfa1, an essential transcriptional factor for osteoblast differentiation, in osteoclastogenesis: Regulation of mRNA expression of osteoclast differentiation factor (ODF) Biochemical and Biophysical Research Communications 1998252 697-702.

51 Kong Y-Y, Yoshida H, Sarosi I, Tan H-L, Timms E, Capparelli C et al. OPGL is a key regulator of osteoclastogenesis, lymphocyte development and lymph-node organogenesis. Nature 1999397 315-323.

52 Quinn JMW, Elliott J, Gillespie MT \& Martin TJ. A combination of osteoclast differentiation factor and macrophage-colony stimulating factor is sufficient for both human and mouse osteoclast formation in vitro. Endocrinology 19981394424 4427.

53 Matsuzaki K, Udagawa N, Takahashi N, Yamaguchi K, Yasuda H, Shima $\mathrm{N}$ et al. Osteoclast differentiation factor (ODF) induces osteoclast-like cell formation in human peripheral blood mononuclear cell cultures. Biochemical and Biophysical Research Communications $1998246199-204$.

54 Udagawa N, Takahashi N, Matsuzaki K, Jimi E, Tsurukai T, Itoh K et al. Osteoblasts/stromal cells activate osteoclast function through osteoclast differentiation factor (ODF). Bone 199823 (Suppl 1) S220 (Abstract no. T072).

55 Jimi E, Akiyama S, Tsurukai T, Kobayashi K, Takahashi N, Udagawa $\mathrm{N}$ et al. Osteoclast differentiation factor (ODF) induces fusion, survival and activation of osteoclasts. Bone 199823 (Suppl 1) S222 (Abstract no. T079).

56 Wong BR, Josien R, Young Lee S, Sauter B, Li H-L, Steinman RM et al. TRANCE (tumor necrosis factor [TNF]-related activationinduced cytokine), a new TNF family member predominantly expressed in $\mathrm{T}$ cells, is a dendritic cell-specific survival factor. Journal of Experimental Medicine 1997186 2075-2080.

57 Darnay BG, Haridas V, Ni J, Moore PA \& Aggarwal BB. Characterization of the intracellular domain of receptor activator of NF- $\kappa \mathrm{B}$ (RANK). Journal of Biological Chemistry 1998273 20551-20555.

58 Hsu H, Lacey DL, Dunstan CR, Solovyev I, Colombero A, Timms E et al. Tumor necrosis factor receptor family member RANK mediates osteoclast differentiation and activation induced by osteoprotegerin ligand. Proceedings of the National Academy of Sciences of the USA $1999963540-3545$.

59 Nakagawa N, Kinosaki M, Yamaguchi K, Shima N, Yasuda H, Yano $\mathrm{K}$ et al. RANK is the essential signaling receptor for osteoclast differentiation factor in osteoclastogenesis. Biochemical and Biophysical Research Communications 1998253 395-400.

60 Wong BR, Josien R, Young Lee S, Vologodskaia M, Steinman RM \& Choi Y. The TRAF family of signal transducers mediates NF- $\kappa \mathrm{B}$ activation by the TRANCE receptor. Journal of Biological Chemistry $199827328355-28359$.

61 Arch RH, Gedrich RW \& Thompson CB. Tumor necrosis factor receptor-associated factors (TRAFs) - a family of adapter proteins that regulates life and death. Genes and Development 199812 $2821-2830$.

62 Galibert L, Tometsko ME, Anderson DM, Cosman D \& Dougall WC. The involvement of multiple tumor necrosis factor receptor (TNFR)-associated factors in the signaling mechanism of receptor activator of NF- $\kappa \mathrm{B}$, a member of the TNFR superfamily. Journal of Biological Chemistry 1998273 34120-34127.

63 Dadgostar H \& Cheng G. An intact zinc finger is required for tumor necrosis factor receptor-associated factor-mediated nuclear factor- $\kappa \mathrm{B}$ activation but is dispensible for c-Jun N-terminal kinase signaling. Journal of Biological Chemistry 1998273 2477524780.

64 Wang C-Y, Mayo MW, Korneluk RG, Goeddel DV \& Baldwin AS. $\mathrm{NF}-\kappa \mathrm{B}$ antiapoptosis: induction of TRAF1 and TRAF2 and c-IAP1 and c-IAP2 to suppress caspase-8 activation. Science 1998281 1680-1683.

65 Lomaga MA, Yeh W-C, Sarosi I, Duncan GS, Furlonger C, Ho A et al. TRAF6-deficiency results in osteopetrosis and defective interleukin-1, CD40 and LPS signaling. Genes and Development 199913 1015-1024.

66 Hing L, Carlson L, Siebenlist U \& Boyce BF. Mechanisms by which $\mathrm{NF}-\kappa \mathrm{B}$ regulates osteoclast numbers. Bone 199823 (Suppl 1) S190 (Abstract no. 1172).

67 Riggs BL, Khosla S \& Melton LJ. A unitary model for involutional osteoporosis: Estrogen deficiency causes both type I and type II osteoporosis in postmenopausal women and contributes to bone loss in aging men. Journal of Bone and Mineral Research 199813 $763-773$.

68 Oursler MJ, Cortese C, Keeting PE, Anderson MA, Bonde SK, Riggs $\mathrm{BL}$ et al. Modulation of transforming growth factor- $\beta$ production in normal human osteoblast-like cells by $17 \beta$ estradiol and parathyroid hormone. Endocrinology 1991129 3313-3320.

69 Hughes DE, Dai A, Tiffee JC, Li HH \& Mundy GR. Estrogen promotes apoptosis of murine osteoclasts mediated by TGF-beta. Nature Medicine 19972 1132-1136.

70 Yano K, Tsuda E, Washida N, Kobayashi F, Goto M, Harada A et al. Immunological characterization of circulating osteoprotegerin/ osteoclastogenesis inhibitory factor: Increased serum concentrations in postmenopausal women with osteoporosis. Journal of Bone and Mineral Research $199914518-527$.

71 Arrighi HM, Hsieh A, Wong H, Khoo H, Reyes A, Asbury D et al. Osteoprotegerin serum levels in healthy volunteers. Bone 199823 (Suppl 1) S298 (Abstract no. T411).

72 Sarma U, Edwards M, Motoyoshi K \& Flanagan AM. Inhibition of bone resorption by $17 \beta$-estradiol in human bone marrow cultures. Journal of Cellular Physiology 1998175 99-108.

73 Kimble RB, Srivastava S, Ross FP, Matayoshi A \& Pacifici R. Estrogen deficiency increases the ability of stromal cells to support 
murine osteoclastogenesis via an interleukin-1- and tumor necrosis factor-mediated stimulation of macrophage colonystimulating factor production. Journal of Biological Chemistry $19964628890-28897$.

74 Lukert B \& Raisz LG. Glucocorticoid-induced osteoporosis: pathogenesis and management. Annals of Internal Medicine $1990112352-364$.

75 Reid IR. Glucocorticoid osteoporosis - mechanisms and management. European Journal of Endocrinology 1997137 209-217.

76 Delany AM, Dong Y \& Canalis E. Mechanisms of glucocorticoid action in bone cells. Journal of Cellular Biochemistry 199456295 302.

77 Canalis E. Mechanisms of glucocorticoid action in bone: Implications to glucocorticoid-induced osteoporosis. Journal of Clinical Endocrinology and Metabolism 199681 3441-3447.

78 Conaway HH, Grogorie D \& Lerner UH. Stimulation of neonatal mouse calvarial bone resorption by the glucocorticoids hydrocortisone and dexamethasone. Journal of Bone and Mineral Research 199611 1419-1429.

79 Kaji H, Sugimoto T, Kanatani M, Nishiyama K \& Chihara K. Dexamethasone stimulates osteoclast-like cell formation by directly acting on hemopoietic blast cells and enhances osteoclast-like cell formation stimulated by parathyroid hormone and prostaglandin E2. Journal of Bone and Mineral Research 199712 $734-741$.

80 Gronowicz G, McCarthy MB \& Raisz LG. Glucocorticoids stimulate resorption in fetal rat parietal bones in vitro. Journal of Bone and Mineral Research 19905 1223-1230.

81 Chiodini I, Carnevale V, Torlontano M, Fusilli S, Gugglielmi G, Pileri $\mathrm{M}$ et al. Alterations of bone turnover and bone mass at different skeletal sites due to pure glucocorticoid excess: study in eumenorrheic patients with Cushing's syndrome. Journal of Clinical Endocrinology and Metabolism 199883 1863-1867.

82 Riggs BL, Jowsey J \& Kelly PJ. Quantitative microradiographic study of bone remodeling in Cushing's syndrome. Metabolism $196615773-780$.

83 Dempster D. Bone histomorphometry in glucocorticoid-induced osteoporosis. Journal of Bone and Mineral Research 199813 137-141.

84 Felix R, Hofstetter W \& Cecchini MG. Recent developments on the understanding of the pathophysiology of osteopetrosis. European Journal of Endocrinology 1996134 143-156.

85 Iotsova V, Caamano J, Loy J, Yang Y, Lewin A \& Bravo R. Osteopetrosis in mice lacking NF- $\kappa \mathrm{B} 1$ and NF- $\kappa \mathrm{B} 2$. Nature Medicine 19983 1285-1289.

86 Yoshida H, Hayashi S, Kunisada T, Ogawa M, Nishikawa S, Okamura $\mathrm{H}$ et al. The murine mutation osteopetrosis is in the coding region of the macrophage colony stimulating factor gene. Nature $1990345442-444$.

87 Horwood NJ, Kartsgiannis V, Lam MHC, Romas E, Quinn JMW, Martin TJ et al. Activated T cells are capable of inducing osteoclast formation: a mechanism for rheumatoid arthritis. Bone 199823 (Suppl 1) S214 (Abstract no. T046).

88 Kotake S, Udagawa N, Takahashi N, Yano K, Tsuda E, Higashio K et al. Presence of osteoclastogenesis inhibitory factor/osteoprotegerin in synovial fluids from patients with rheumatoid arthritis. Arthritis and Rheumatism 199841 (Suppl) S320 (Abstract no. 1727).

Received 29 January 1999

Accepted 31 May 1999 